\title{
Tolerability of Concurrent Chemoradiotherapy with Gemcitabine (GemX), with and without prior Neoadjuvant Chemotherapy in Muscle Invasive Bladder Cancer
} DOI:

10.1016/j.jijobp.2016.11.040

\section{Document Version \\ Accepted author manuscript}

Link to publication record in Manchester Research Explorer

Citation for published version (APA):

Thompson, C., Joseph, N., Sanderson, B., Logue, J., Wylie, J., Lyons, J., Anandadas, C. N., \& Choudhury, A. (2017). Tolerability of Concurrent Chemoradiotherapy with Gemcitabine (GemX), with and without prior Neoadjuvant Chemotherapy in Muscle Invasive Bladder Cancer. International Journal of Radiation: Oncology Biology - Physics. https://doi.org/10.1016/j.ijrobp.2016.11.040

\section{Published in:}

International Journal of Radiation: Oncology - Biology - Physics

\section{Citing this paper}

Please note that where the full-text provided on Manchester Research Explorer is the Author Accepted Manuscript or Proof version this may differ from the final Published version. If citing, it is advised that you check and use the publisher's definitive version.

\section{General rights}

Copyright and moral rights for the publications made accessible in the Research Explorer are retained by the authors and/or other copyright owners and it is a condition of accessing publications that users recognise and abide by the legal requirements associated with these rights.

\section{Takedown policy}

If you believe that this document breaches copyright please refer to the University of Manchester's Takedown Procedures [http://man.ac.uk/04Y6Bo] or contact uml.scholarlycommunications@manchester.ac.uk providing relevant details, so we can investigate your claim.

\section{OPEN ACCESS}




\section{Accepted Manuscript}

Tolerability of Concurrent Chemoradiotherapy with Gemcitabine (GemX), with and without prior Neoadjuvant Chemotherapy in Muscle Invasive Bladder Cancer

Catherine Thompson, Nuradh Joseph, Benjamin Sanderson, John Logue, James Wylie, Tony Elliott, Jeanette Lyons, Carmel Anandadas, Ananya Choudhury

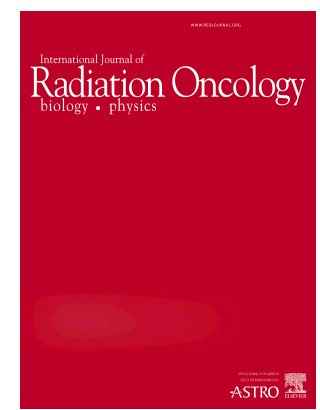

PII: S0360-3016(16)33498-8

DOI: 10.1016/j.jijrobp.2016.11.040

Reference: $\quad$ ROB 23929

To appear in: International Journal of Radiation Oncology $•$ Biology $•$ Physics

Received Date: 21 April 2016

Revised Date: 14 November 2016

Accepted Date: 21 November 2016

Please cite this article as: Thompson C, Joseph N, Sanderson B, Logue J, Wylie J, Elliott T, Lyons J, Anandadas C, Choudhury A, Tolerability of Concurrent Chemoradiotherapy with Gemcitabine (GemX), with and without prior Neoadjuvant Chemotherapy in Muscle Invasive Bladder Cancer, International Journal of Radiation Oncology • Biology • Physics (2016), doi: 10.1016/j.jrobp.2016.11.040.

This is a PDF file of an unedited manuscript that has been accepted for publication. As a service to our customers we are providing this early version of the manuscript. The manuscript will undergo copyediting, typesetting, and review of the resulting proof before it is published in its final form. Please note that during the production process errors may be discovered which could affect the content, and all legal disclaimers that apply to the journal pertain. 
Title

Tolerability of Concurrent Chemoradiotherapy with Gemcitabine (GemX), with and without prior Neoadjuvant Chemotherapy in Muscle Invasive Bladder Cancer

\section{Short title}

GemX with and without prior neoadjuvant chemotherapy

full first and last name

Authors' names and affiliations

Catherine Thompson**, Nuradh Josepht, Benjamin Sanderson**, John Logue**, James Wylie**, Tony Elliott**, Jeanette Lyons**, Carmel Anandadas**, Ananya Choudhury** oo

(Italic indicates joint first author)

* University Hospitals of Morecambe Bay

- Rosemere Cancer Centre

**Department of Clinical Oncology, The Christie NHS Foundation Trust , Manchester Academic Health Science Centre, Manchester, M20 4BX, UK

${ }^{\circ}$ Division of Molecular and Clinical Cancer Sciences, School of Medical Sciences, Faculty of Biology, Medicine and Health, University of Manchester, Manchester Academic Health Science Centre, Manchester M20 4BX, UK

† General Hospital Polonnaruwa, Ministry of Health, Sri Lanka

\section{Corresponding author including telephone and e-mail address}

Dr Catherine Thompson

Consultant Clinical Oncologist

Royal Lancaster Infirmary

Ashton Road, Lancaster

Lancashire, LA1 4RP

Telephone: 01229403621

Email: Catherine.thompson@mbht.nhs.uk

\section{Conflict of interest statement}

Nil

\section{Acknowledgments}

We gratefully acknowledge Jason Kennedy for providing database management. 
Tolerability Of Concurrent Chemoradiotherapy With Gemcitabine (GemX), with and without prior Neoadjuvant Chemotherapy In Muscle Invasive Bladder Cancer

\section{Summary}

Chemoradiotherapy for muscle invasive bladder cancer is an accepted alternative radical treatment approach to cystectomy. This study reports tolerability and toxicity including patient reported outcomes for patients treated with hypofractionated radiotherapy and gemcitabine in this setting, comparing these outcomes in those receiving neoadjuvant chemotherapy prior to definitive treatment to those who underwent chemoradiotherapy alone. We demonstrated no increased toxicity or decline in treatment completion with the combination of chemoradiotherapy with neoadjuvant chemotherapy. 


\section{ABSTRACT}

2 Purpose: The aim of this study is to assess the tolerability of concurrent chemoradiotherapy

3 with gemcitabine (GemX) in muscle invasive bladder cancer (MIBC) following neoadjuvant

4 chemotherapy (neoGemX) using patient and provider reported outcomes.

\section{$5 \quad$ Materials and Methods:}

6 Seventy eight patients were treated with GemX. Thirty-eight received prior neoadjuvant

7 chemotherapy (NAC). Patients were prospectively assessed during treatment and at 6 weeks

8 and 12 months post treatment completion. Radiotherapy was given to a total dose of 52.5

9 Gy in 20 fractions with weekly concurrent gemcitabine chemotherapy $100 \mathrm{mg} / \mathrm{m}^{2}$. Toxicity

10 was assessed by care provider and using a patient reported outcome questionnaire

11 collecting Lent Soma (LS) scores and statistically compared at baseline and 12 months and

12 between the neoGem $X$ and GemX groups.

\section{Results}

14 Median duration of follow up was 15.9 months. Radiotherapy completion rate was $95 \%$ and $1596 \%$ of patients completed at least 3 cycles of gemcitabine. Bowel toxicity $\geq$ grade 3 was 16 reported in 7/38 (18\%) of patients in the neoGemX group and 5/25 (20\%) in the GemX 17 group. Three GemX and 2 neoGem $X$ patients had grade $\geq 3$ urinary toxicity.

18 Forty nine patients completed questionnaires and were included in the analysis. LS scores 19 showed an expected peak by week 4 of treatment. There was no statistically significant 20 difference between mean scores at baseline and 12 months post treatment completion, or 21 between the neoGemx and Gemx groups.

\section{Conclusion}

23 This study demonstrates that GemX, alone or following NAC, has manageable toxicity and 24 acceptable treatment completion rates. Allowing for small patient numbers and the non 25 randomised nature of this study, these results do not suggest any additional toxicity from 26 the use of NAC prior to GemX. 


\section{Introduction}

2

3 Bladder cancer has an incidence of over 10,000 new cases per year in the UK, with nearly

$425 \%$ of cases being classified as MIBC (1). Over $90 \%$ of these are histologically transitional cell carcinoma (TCC). Traditionally the gold standard of treatment for these patients has been with radical cystectomy. Bladder preservation with transurethral resection of bladder tumour (TURBT) followed by radical radiotherapy with a radiosensitiser, with salvage cystectomy in cases of recurrent disease, has become accepted in clinical practice as an alternative strategy. Recent guidance published in the UK now suggests that all patients fit for radical treatment should be offered both cystectomy and bladder preservation as equivalent options (2). There is no randomised controlled trial (RCT) data comparing these two strategies, but outcomes appear to be similar, with 5 year overall survival rates ranging from $30-60 \%$ (3-5). There is now a strong evidence base for use of platinum containing NAC in addition to definitive treatment $(6,7)$. Radiosensitisation strategies using a variety of concurrent chemotherapy regimes or an alternative using carbogen and nicotinamide (CON) (8-24) have also demonstrated favourable outcomes. Weekly gemcitabine and moderately hypofractionated radiotherapy (GemX) has previously been studied in a phase II trial and demonstrated good rates of local control and tolerability (25).

The majority of patients in the pivotal trials confirming the superiority of radiosensitisation did not receive NAC prior to their definitive treatment $(8,9,25)$. Despite this, NAC has become accepted in UK clinical practice as a standard treatment option for patients treated with bladder preservation strategies.

The aim of this prospective cohort study is to compare both provider reported toxicity and patient reported toxicity in patients receiving NAC followed by GemX and GemX alone.

\section{Methods}

\section{Patients}

32 All patients undergoing GemX between May 2010 and August 2013, treated at a single 33 cancer centre, were eligible for the study. Patients had MIBC confirmed with TURBT and 34 were staged (American Joint Committee on Cancer 2010) using cross sectional imaging of 
1 thorax, abdomen and pelvis. Patients undergoing pelvic nodal irradiation and patients who were planned to receive radiotherapy alone, were excluded. Patients were selected for NAC by their performance status, comorbidities and renal function.

4 The study was approved by the appropriate local research committee and patients provided informed written consent for treatment as per standard practice. Treatment: Radiotherapy was given to a total dose of $52.5 \mathrm{~Gy}$ in 20 fractions within 28 days with 4 cycles of weekly concurrent gemcitabine chemotherapy $100 \mathrm{mg} / \mathrm{m}^{2}$ given one hour before radiotherapy on days $1,8,15$, and 22 . Radiotherapy was planned using a three dimensional conformal technique, with a clinical target volume including the whole empty bladder expanded with a $1.5 \mathrm{~cm}$ margin in all directions to form a planning target volume.

11 NAC using a platinum doublet regime was given at physician discretion after assessment of

12 isotope glomerular filtration rate (GFR).

\section{Assessment of Toxicity}

15 Toxicity was assessed at baseline, weekly during radiotherapy and at 6 weeks and 12 months 16 post completion of treatment. Provider reported toxicity was prospectively assessed using 17 the Radiation Therapy Oncology Group (RTOG) acute and late toxicity criteria Assessment 18 was performed by a nurse clinician or physician before and during chemoradiotherapy and 19 at 12 months post completion of treatment and via telephone with a nurse clinician or 20 research nurse at 6 weeks following completion of treatment. Patients underwent 3-6 21 monthly cystoscopic follow up as per local policy. All cases wherein patients experienced grade 3 acute or late bowel toxicity were retrospectively reviewed to determine if any predisposing risk factors could be identified in the RT plan, on treatment imaging or preexisting comorbidities.

Patient reported toxicity outcomes were collected using a previously validated late effects in normal tissues subjective, objective, management, and analytic scales (LENT/SOMA; subjective part) pelvic radiotherapy questionnaire. Separate male and female questionnaires were used covering domains of bowel, urinary and sexual function. Toxicity was scored from $300=$ no toxicity to $4=$ maximum level of toxicity where a score of $\geq 2$ is considered to represent 31 clinically significant toxicity. Questionnaires were delivered to patients at the time of 32 attendance for radiotherapy during treatment and subsequently by post. 


\section{Statistical analysis}

2 Male and female questionnaires were analysed separately. Mean total scores for each domain of the LS questionnaire were calculated. Patients who had not completed a questionnaire at baseline and at least one other time point were excluded from the analysis.

Wilcoxon signed rank test was used to compare baseline scores to scores at 12 months for the bowel and urinary function domains for all patients. The differences from baseline to scores at 12 months were compared between the NeoGemX and Gem $X$ group using the Wilcoxon rank sum test. Sexual scores are reported, but were not statistically compared due to the small number of responses. Baseline characteristics between groups, including age, performance status, T stage and hydronephrosis, were compared using the Wilcoxon rank sum test for age and the chi-squared test for categorical variables. Logistic regression analysis was performed to account for imbalances in confounding factors between the two groups in a model incorporating age, performance status, tumour stage and presence of hydronephrosis.

Loco-regional disease-free survival, distant metastases free survival and overall survival were compared between the two groups using Kaplan-Mier survival analysis and the log-rank test. The effect of tumour stage, performance status and age in addition to use of neoadjuvant chemotherapy was assessed in a multivariate model using the Cox proportional hazards model.

\section{Results}

\section{Patient characteristics} Seventy eight patients, treated between 18/05/2010 and 13/08/2013, were included. Thirty eight of these patients received prior NAC. Median duration of follow up was 15.9 months (range 0.8-50.5 months), 14.1 months (range 0.8-45.4 months) in the GemX group and 16.1 months (range 0.8-45.4 months) in the neoGemX group. Patient characteristics in the GemX alone and neoGemX groups are shown in table 1. NeoGemX patients were significantly younger and had a trend towards better performance status than GemX patients. Mean GFR in patients receiving NAC was $89 \mathrm{ml} / \mathrm{min}$. 
$1 \quad$ Treatment details

2 Thirty four patients received cisplatin and gemcitabine doublet NAC, 4 received carboplatin

3 rather than cisplatin due to renal impairment, 1 had small cell histology and received

4 cisplatin and etoposide. Thirty six patients received 3 cycles of chemotherapy, the remaining

52 patients received 6 cycles. Chemoradiotherapy completion rates are shown in table 2.

7 Toxicity

8 Provider reported toxicity

9 Maximum acute and late RTOG bowel and urinary toxicity in the 2 groups is shown in figure 101.

11 Grade 1-2 acute bowel toxicity was present in 65/78 patients by week 4, with 7/78 patients

12 experiencing grade $\geq 3$ toxicity. By 6 weeks post treatment $25 / 78$ patients had ongoing

13 grade 1-2 toxicity and grade 3 toxicity was seen in 3/78 patients. Late bowel toxicity was

14 assessed at 12 months or more of follow up in 58/78 patients, 41 patients reported no

15 ongoing bowel toxicity. Two patients had late toxicity of grade $\geq 3$. One patient developed

16 severe colitis requiring colostomy 12 months after treatment. This patient was found to

17 have poor bowel function at baseline with no definite underlying pathology and had

18 declined cystectomy. The second patient had a bowel perforation, during a course of

19 palliative chemotherapy for metastatic disease, at 9.5 months after treatment. Although two

20 patients had increased small bowel volume within the high dose region on imaging, there

21 was no associated toxicity and in the remaining patients, no additional risk factors were

22 identified.

24 Significant urinary toxicity was less commonly observed, with grade 3 toxicity only reported 25 in 5 patients at any time point. Late urinary toxicity was assessed in 51/78 patients. Eight

26 patients reported ongoing urinary toxicity which was grade $\leq 2$ in all cases.

\section{Patient reported toxicity outcomes}

29 Forty nine patients completed questionnaires at baseline and at least one other time point

30 and were included in the questionnaire analysis. The number of patients completing

31 questionnaires at each time point and the mean total scores for bowel, urinary and sexual

32 functions are shown in table 3.

33 Figure 2 demonstrates mean LS scores for bowel and urinary function for male patients in 34 the two groups. 
2 In all patient groups mean LS scores peaked at 4 weeks and were returning to baseline by 12

3 months.

4

5 There was no statistically significant change in LS scores for bowel $(p=0.48)$ or urinary

6 function ( $p=0.19)$ from baseline to 12 months.

7 There was no statistically significant difference in LS scores between the GemX and neoGem $X$ groups ( $p=0.44$ for bowel and $p=0.11$ for urinary function), confirmed on logistic regression analysis ( $p=0.31$ for bladder and $p=0.09$ for bowel) correcting for confounding

10 factors.

\section{Outcomes}

\section{3 month cystoscopy response}

14 Cystoscopy results at 3 month post completion of GemX were available in 66/78 patients 15 (85\%). Of the patients for whom no 3 month cystoscopy result was available, 3 were from 16 the neoGemX group and the remainder received GemX alone Two did not have cystoscopic 17 assessment due to presence of metastatic disease, 7 due to deterioration in clinical 18 condition, the remainder were lost to follow up. Complete response was demonstrated in $1961 / 66$ cases (92\%), 30 in the GemX group and 31 in the neoGemX group (see table 4).

\section{Disease free survival, overall survival and cystectomy rates}

Local and distant recurrence and cystectomy rates and cancer related and cancer unrelated death rates are shown in table 4. Disease free survival (DFS), defined as freedom from invasive local or metastatic recurrence, and overall survival (OS) outcomes for the neoGemX and GemX groups are shown in figure 3. Two year DFS was $0.65(95 \% \mathrm{Cl}, 0.48-0.87)$ for the GemX group and 0.81 (95\% Cl 0.68-0.96) for the neoGemx group, while the two year OS was 0.67 ( $\mathrm{Cl} 0.52$ - 0.87) for the GemX patients and 0.69 ( $\mathrm{Cl} 0.51-0.92$ ) for the neoGemX patients. There was no statistically significant difference in DFS $(p=0.60)$ or OS $(p=0.28)$ between the neoGemX and GemX groups. This remained the case after correcting for tumour stage, age and performance status in a multivariate Cox proportional hazards model (DFS $p=0.59$ OS $\mathrm{p}=0.61)$. Two year DFS was $0.65(95 \% \mathrm{Cl}, 0.48-0.87)$ for the $\mathrm{Gem} X$ group and $0.81(95 \% \mathrm{Cl}$

$320.68-0.96)$ for the neoGemx group, while the two year OS was $0.67(\mathrm{Cl} 0.52-0.87)$ for the 33 GemX patients and 0.69 (Cl 0.51-0.92) for the neoGemX patients. 


\section{Discussion}

Traditionally, radical radiotherapy for MIBC was reserved for those patients who were considered unfit for definitive surgery. There is now an increasing role for bladder preservation, using NAC prior to radical radiotherapy with radiosensitisation, with salvage cystectomy for recurrent MIBC. The BA06 RCT demonstrated a $6 \%$ improvement in overall survival at 10 years with the addition of NAC to definitive treatment (6), which was confirmed in the $A B C$ meta-analysis, which included results from 10 RCTs and demonstrated an improvement in 5 year overall survival of $5 \%(7)$.

Two landmark UK phase III studies have demonstrated a clear role for radiotherapy with radiosensitisation with either concurrent chemotherapy or CON. The BC2001 RCT compared chemoradiotherapy using $\mathrm{MMC} / 5 \mathrm{FU}$ to radiotherapy alone and demonstrated improved loco-regional disease free survival at two years, $67 \%$ compared to $54 \%(P=0.03)(8)$. The BCON RCT compared radiotherapy alone to radiotherapy with CON. CON produced a small non-significant improvement in cystoscopic control at 6 months but a significant difference in overall survival ( $59 \%$ and $46 \% \mathrm{P}=0.04)(9)$. Late morbidity was similar in both trial arms in both studies. Both studies allowed the use of conventional radiotherapy fractionation with $64 \mathrm{~Gy}$ in 32 fractions over 6.5 weeks or moderately hypofractionated fractionation with 55Gy in 20 fractions over 4 weeks. Outcomes using cisplatin containing chemoradiotherapy have also been reported in studies previously, with one RCT and other large retrospective series reporting favourable outcomes compared to others in the literature (18-24). An overview of radiotherapy vs chemoradiotherapy studies, 11 of which included patients receiving prior NAC, demonstrated a consistent improvement in tumour control for chemoradiotherapy (29). However, not all patients are suitable for these regimes. An alternative chemotherapy regime for radiosensitisation, is weekly gemcitabine. Gemicitabine is an established chemotherapy agent for use in bladder cancer and is a known radio-sensitiser. There are several phase I and II studies investigating its use in this context (10-17). A phase II trial has previously been reported, in which gemcitabine was given weekly with hypofractionated radiotherapy (25). A total of 50 patients were treated. Three year cancer-specific survival was $82 \%$, and overall survival was $75 \%$. Forty four patients ( $88 \%$ ) achieved a complete endoscopic response. Four patients underwent cystectomy; three because of recurrent disease and one because of toxicity. 
1 The results of the current study demonstrate comparable tolerability, toxicity and treatment

2 outcomes compared to both the regimes used in the BCON and BC2001 studies and the

3 original phase II gemcitabine study, with at least $95 \%$ of patients completing all radiotherapy

4 and over $90 \%$ completing at least $80 \%$ of prescribed radiosensitisation in all studies. This suggests that GemX is well-tolerated. In addition, there was no evidence of reduced completion rates in patients who received NAC. This supports the finding that NAC does not compromise ability to tolerate definitive chemoradiotherapy. In our study, only $7 / 20$ of the patients who omitted chemotherapy did so due to G3 bowel toxicity. A small proportion of patients will develop toxicity preventing receiving full doses of scheduled radiosensitising agents, regardless of the regime used and this does not appear to compromise the overall treatment outcomes reported. Of the patients who omitted at least 1 cycle of gemcitabine in this study, only one had evidence of residual disease at the time of 3 month cystoscopy. In the total follow up period only 3 additional patients developed recurrence. Allowing for the small number of events seen, there is no obvious decline in treatment outcomes in terms of local control in the small cohort of patients who did not complete all 4 cycles of gemcitabine.

Chemoradiotherapy is recognised to cause an increased risk of acute toxicity compared to radiotherapy alone, although both the $\mathrm{BCON}$ and $\mathrm{BC} 2001$ trials did not report a significant increase in late toxicity with radiosensitisation $(8,9)$. The $B C 2001 \mathrm{RCT}$, demonstrated a rate of grade 3 or more acute bowel toxicity of $9.6 \%$ in patients receiving chemoradiotherapy. In the original phase II GemX study this figure was $8 \%$. Late grade 3 toxicity of any type was reported at $8.3 \%$ in the radiosensitisation arm of BC2001, $7 \%$ for late bowel toxicity in BCON and $4 \%$ in the phase II GemX study.

Allowing for the shorter period of follow up and small number of events seen our results again appear comparable and the rate of late grade 3 bowel toxicity did not appear increased in the NAC group. The low rates of late toxicity were also demonstrated in the return of LS scores towards baseline at 12 months post treatment completion, with no statistically significant difference seen between scores at baseline and 12 months. Sexual

30 toxicity is more difficult to assess, and rates of assessment were low both on provider and 31 patient-reported outcomes.

33 The patient reported outcome questionnaires did not demonstrate any statistically

34 significant difference in LS scores between the neoGemX and GemX group at any time point. 
1 There was however, a trend towards both a higher baseline score and higher scores at each

2 time point in the GemX only arm. The significance of this is uncertain given the small patient

3 numbers and lack of randomisation between the groups. Logistic regression was used to

4 adjust for any difference between factors in the 2 groups, but still did not suggest any significant increase in scores in the neoGemX group.

The rate of cystoscopic complete response at 3 months was $92 \%$ in those patients who had cystoscopy. This does not however, fully reflect local control, as patients who had developed metastatic disease did not proceed to cystoscopy at 3 months. In BCON cystoscopic response was difficult to measure accurately at a given time point due to the variation in

11 timing of first check cystoscopy, thus making it difficult to quantify local control (9). During

12 the follow up period of the present study, 7 patients proceeded to cystectomy,

13 demonstrating that, in this limited follow up period, rates of bladder preservation appear

14 comparable to those reported in the literature. Median overall survival was not reached.

15 Second malignancy, even in this limited follow up period, reflects the burden of additional 16 comorbidities in this group of patients.

The patient-reported outcomes and provider-reported toxicity within this study support the use of NAC prior to definitive chemoradiotherapy. However, this study is based on a limited number of patients, with relatively short follow up. The completeness of weekly provider reported toxicity assessments during treatment was very high, however it must be acknowledged that some patients were lost to follow up and that late toxicity assessment is based on follow up at 12 months post completion of treatment. Whilst the rate of questionnaire completion was sufficient to provide a useful comparison of patient reported outcomes not all patients were compliant, which may have introduced bias.

The outcomes reported are based on a heterogeneous group of patients compared to those included in RCT, including small numbers of node positive patients and those with small cell histology included in the neoGemX group. Although this would be expected to adversely

30 affect the survival outcomes seen, prognostic factors such as these should not affect the 31 toxicity data reported in this study.

33 This study is not a RCT, selection for NAC was based on clinical decisions by treating physicians. Given the prevalence and accepted practice of combining NAC with 
1 chemoradiotherapy, a RCT would be difficult to perform. There was no increase in LS scores

2 seen after adjusting for confounding factors using logistic regression. There was no

3 statistically significant difference between the groups on baseline LS scoresAlthough there

4 was no statistically significant difference between LS scores at any time point between the

5 two groups, there was a trend towards increased toxicity in the GemX only group compared

6 to those receiving neoGemX, supporting that this may be the case.

7

8 In summary, although limited by the small patient numbers and lack of randomisation and

9 potential selection bias, our study supports the use of NAC and GemX for patients being

10 treated with bladder preservation.

11

12

13

14

15

16

17

18

19

20

21

22

23

24

25

26

27

28

29

30

31

32

33

34 


\section{$1 \quad$ List of tables}

2 Table 1: Patient characteristics

3

4 Table 2: Treatment completion rates

5

6 Table 3: Rates of questionnaire completion and mean Lent Soma (LS) scores during and after

7 treatment

8

9 Table 4: Outcomes following treatment with GemX

10

11

12

13

14

15

16

17

18

19

20

21

22

23

24

25

26

27

28

29

30

31

32

33 


\section{$1 \quad$ List of figures}

2

3 Figure 1. RTOG maximum grade of acute and late bowel and urinary toxicity in patients

4 receiving neoGemX and GemX alone. A) acute toxicity B) late toxicity

5

6 Figure 2: A) Lent Soma Questionnaire Mean Bowel Scores for Male Patients B) Lent Soma

7 Questionnaire Mean Urinary Scores for Male Patients

8

9 Figure 3: A) Disease Free Survival and B) Overall Survival outcomes for neoGemX and GemX

10 groups

11

12

13

14

15

16

17

18

19

20

21

22

23

24

25

26

27

28

29

30

31

32

33

34

35 


\section{References}

2

3 1. United Kingdom Cancer Research: Cancer- Stats Report-Bladder Cancer United Kingdom.

4 Cancer Research United Kingdom, 2011.

5

6 2. Huddart RA, Jones R, Choudhury A. A New Dawn for Bladder Cancer? Recommendations

7 from the National Institute for Health and Care Excellence (NICE) on

8 Managing Bladder Cancer. Clin Oncol (R Coll Radiol). 2015;27(7):380-1.

10 3. Mak RH, Hunt D, Shipley WU et al. Long-term outcomes in patients with muscle-invasive

11 bladder cancer after selective bladder-preserving combined-modality therapy: a pooled

12 analysis of Radiation Therapy Oncology Group protocols 8802, 8903, 9506, 9706, 9906, and

13 0233. J Clin Oncol 2014; 32(34):3801-9.

15 4. Kotwal S, Choudhury A, Johnston C, et al. Similar treatment outcomes for radical

16 cystectomy and radical radiotherapy in invasive bladder cancer treated at a United Kingdom 17 specialist treatment center. Int J Radiat Oncol Biol Phys 2008; 70:456-463.

19 5. Booth CM, Siemens DR, Li G, Peng Y, Kong W, Berman DM, Mackillop WJ.

20 Curative therapy for bladder cancer in routine clinical practice: a population-based

21 outcomes study. Clin Oncol (R Coll Radiol). 2014;26(8):506-14.

23 6. Griffiths G, Hall R, Sylvester R et al. International phase III trial assessing neoadjuvant 24 cisplatin, methotrexate, and vinblastine chemotherapy for muscle-invasive bladder cancer: 25 long-term results of the BA06 30894 trial. J Clin Oncol. 2011; 29:171-2177

7. Advanced Bladder Cancer (ABC) Meta-analysis Collaboration. Neoadjuvant chemotherapy

28 in invasive bladder cancer: update of a systematic review and meta-analysis of individual

29 patient data advanced bladder cancer ( $A B C$ ) meta-analysis collaboration. Eur Urol

$30 \quad 2005 ; 48(2): 202-5$.

32 8. James ND, Hussein SA, Hall E et al. Radiotherapy with or without chemotherapy in muscle33 invasive bladder cancer. N Engl J Med. 2012;366(16):1477-88 
1 9. Hoskin PJ, Rojas Am, Benzten SM et al. Radiotherapy with Carbogen and nicotinamide in

2 Bladder Carcinoma. J Clin Oncol 2010; 28 (33): 4912-4918

3

4 10. Gogna NK, Matthews JH, Turner SL, et al: Efficacy and tolerability of concurrent weekly

5 low dose cisplatin during radiation treatment of localised muscle invasive bladder

6 transitional cell carcinoma: A report of two sequential phase II studies from the Trans

7 Tasman Radiation Oncology Group. Radiother Oncol. 2006;81:9-17

9 11. Hussian MH, Glass TR, Forman J, et al: Combination cisplatin, 5 -fluorouracil and radiation

10 therapy for locally advanced unresectable or medically unfit bladder cancer cases: A

11 Southwest Oncology Group Study. J Urol 2001;165:56-61

13 12. Sauer R, Dunst J, Altendorf-Hofmann A, et al: Radiotherapy with and without cisplatin in 14 bladder cancer. Int J Radiat Oncol Biol Phys. 1990;19:687-691

13. Zietman AL, Shipley WU, Kaufman DS, et al: A phase I/II trial of transurethral surgery

17 combined with concurrent cisplatin, 5-fluorouracil and twice daily radiation followed by 18 selective bladder preservation in operable patients with muscle invading bladder cancer. $J$

19 Urol .1998;160:1673-1677

21 14. Chauvet B, Brewer Y, Fe' lix-Faure C, et al. Concurrent cisplatin and radiotherapy for 22 patients with muscle invasive bladder cancer who are not candidates for radical cystectomy.

23 J Urol. 1996;156:1258-1262

15. Chen WC, Liaw CC, Chuang CK, et al. Concurrent cisplatin, 5-fluorouracil, leucovorin, and radiotherapy for invasive bladder cancer. Int J Radiat Oncol Biol Phys. 2003;56:726-733 
1 17. Long-Term Outcomes of Selective Bladder Preservation by Combined-Modality Therapy

2 for Invasive Bladder Cancer: The MGH Experience. Re: Jason A. Efstathiou, Daphna Y, et al.

3 Eur Urol. 2012;61(4):705-711.

4

5 18. Caffo O, Fellin G, Graffer U, et al. Phase I study of gemcitabine and radiotherapy plus cisplatin after transurethral resection as conservative treatment for infiltrating bladder cancer. Int J Radiat Oncol Biol Phys. 20013;57:1310-1316

19. Kent E, Sandler H, Montie J, et al. Combined-modality therapy with gemcitabine and radiotherapy as a bladder preservation strategy: results of a phase I trial. J Clin Oncol.

$11 \quad 2014 ; 22: 2540-2545$

20. Sangar VK, McBain CA, Lyons J, et al. Phase I study of conformal radiotherapy with

14 concurrent gemcitabine in locally advanced bladder cancer. Int J Radiat Oncol Biol Phys.

$15 \quad 2015 ; 61: 420-425$

17 21. Caffo O, Fellin G, Graffer U, et al. Gemcitabine and radiotherapy plus cisplatin after 18 transurethral resection as conservative treatment for infiltrating bladder cancer: Long-term 19 cumulative results of 2 prospective single-institution studies. Cancer. 2011;117:1190-1196

22. Kragelj B, Lijana ZK. Phase I study of radiochemotherapy with gemcitabine in invasive bladder cancer. Radiother Oncol. 2012;102:412-415

23. Azria D, Riou O, Rebillard X, et al. Combined chemoradiation therapy with twice-weekly gemcitabine and cisplatin for organ preservation in muscle-invasive bladder cancer: longterm results of a phase 1 trial. Int J Radiat Oncol Biol Phys. 2014;88:853-859 gemcitabine in patients with locally advanced inoperable transitional cell carcinoma of the urinary bladder and/or in patients ineligible for surgery: a phase I trial. Ann Oncol 
1 25. Choudhury A, Swindell R, Logue JP et al. Phase II study of conformal hypofractionated

2 radiotherapy with concurrent gemcitabine in muscle-invasive bladder cancer. J Clin Oncol.

$3 \quad 2011 ; 29(6) ; 733-8$.

4

5

6

7

8 


\section{ACCEPTED MANUSCRIPT}

Table 1: Patient characteristics

\begin{tabular}{|l|l|l|l|}
\hline Characteristic & NeoGemX $(\mathbf{n = 3 8 )}$ & GemX alone $(\mathbf{n = 4 0 )}$ & p value** \\
\hline Median age years (range) & $67.5(53-78)$ & $75.5(54-82)$ & $<0.01$ \\
\hline Performance status $*$ & $0=251=12$ & $0=17$ 1=20 2=2 & 0.06 \\
\hline Histology: TCC only & 34 & 37 & 0.9 \\
\hline $\begin{array}{l}\text { Histology: Other component } \\
\text { present }\end{array}$ & SCC: 2, sarcomatoid: 1 & $\begin{array}{l}\text { Sarcomatoid: } 2, \\
\text { Neuroendocrine: } 1\end{array}$ & \\
\hline Histology: non TCC & 1 (small cell) & 0 & - \\
\hline Carcinoma in situ & 6 & 2 & 0.2 \\
\hline T stage & T2: 30 T3: 6 T4: 2 & T2: 27 T3: 12 T4: 1 & 0.4 \\
\hline
\end{tabular}

* not documented in 2 cases **Wilcoxon's rank sum test used for age, chi-square test used for other factors 
Table 2: Treatment completion rates

\begin{tabular}{|l|l|}
\hline Treatment & Completion rate $\mathbf{n}=\mathbf{7 8}$ \\
\hline Radiotherapy (20 fractions) & $74(95 \%)$ \\
\hline 4 cycles of gemcitabine concurrently * & $58(78 \%)$ \\
\hline At least 3 cycles of gemcitabine cncurrently & $75(96 \%)$ \\
\hline
\end{tabular}

*due to $\mathrm{G} \geq 3 \mathrm{GI}$ toxicity in 8 cases, $\mathrm{G} \geq 3$ GU toxicity in 5 cases 
Table 3: Rates of questionnaire completion and mean Lent Soma (LS) scores during and after treatment.

\begin{tabular}{|c|c|c|c|c|c|c|c|c|c|}
\hline & \multirow{2}{*}{\multicolumn{8}{|c|}{ Time Point (mean scores shown in brackets) }} \\
\hline & & & & & & & & & \\
\hline & & \multicolumn{2}{|c|}{ Week 1 (baseline) } & \multicolumn{2}{|c|}{$\begin{array}{c}\text { Week } 4 \text { (final week } \\
\text { of treatment) }\end{array}$} & \multicolumn{2}{|c|}{$\begin{array}{l}6 \text { weeks post } \\
\text { treatment } \\
\text { completion }\end{array}$} & \multicolumn{2}{|c|}{$\begin{array}{c}12 \text { months post } \\
\text { treatment } \\
\text { completion }\end{array}$} \\
\hline \multicolumn{2}{|c|}{ Patient Group } & Bowel & Urinary & Bowel & Urinary & Bowel & Urinary & Bowel & Urinary \\
\hline \multirow[b]{2}{*}{ Male } & Gemx & $19(2.6)$ & $19(3)$ & $14(11.1)$ & $13(8.2)$ & $9(7.4)$ & $7(5.2)$ & $7(1.4)$ & $7(3.6)$ \\
\hline & NeoGemX & $22(1.3)$ & $22(1.5)$ & $14(8.3)$ & $14(5.1)$ & $13(5.0)$ & $13(3.5)$ & $8(1.8)$ & $9(2.2)$ \\
\hline \multirow[b]{2}{*}{ Female } & Gemx & $3(0.7)$ & $2(5.5)$ & $1(22.0)$ & $1(1.0)$ & 0 & 0 & $1(1.0)$ & $1(1.0)$ \\
\hline & NeoGemX & $5(1.8)$ & $5(7.6)$ & $3(2.3)$ & $3(4.3)$ & 0 & 0 & $2(0.0)$ & $2(8.0)$ \\
\hline
\end{tabular}


Table 4: Outcomes following treatment with GemX.

\begin{tabular}{|l|l|}
\hline Event & $\begin{array}{l}\text { No. patients } \\
\text { total } \mathbf{n}=\mathbf{7 8} \text { assessed at } \mathbf{3} \text { month cystoscopy } \mathbf{n}=6 \mathbf{6}\end{array}$ \\
\hline Residual disease at 3 month cystoscopy & $\begin{array}{l}\text { Muscle invasive: } 3 \\
\text { Superficial: } 2\end{array}$ \\
\hline $\begin{array}{l}\text { Recurrent superficial disease treated with } \\
\text { intravesical therapy }\end{array}$ & 5 \\
\hline Recurrent MIBC* & 11 \\
\hline Cystectomy & $\begin{array}{l}\text { Muscle invasive recurrence: } 6 \\
\text { Recurrent superficial disease and CIS: } 1\end{array}$ \\
\hline Metastatic disease & 15 \\
\hline Death:cancer related & 8 \\
\hline Death: unrelated ${ }^{* * *}$ & 16 \\
\hline
\end{tabular}

* 4 patients not suitable for cystectomy, 2 due to metastatic disease, 1 inoperable at time of attempted surgery 
Figure 1.

1a: Maximum acute toxicity: weeks 1-4 and 6 weeks post treatment completion.

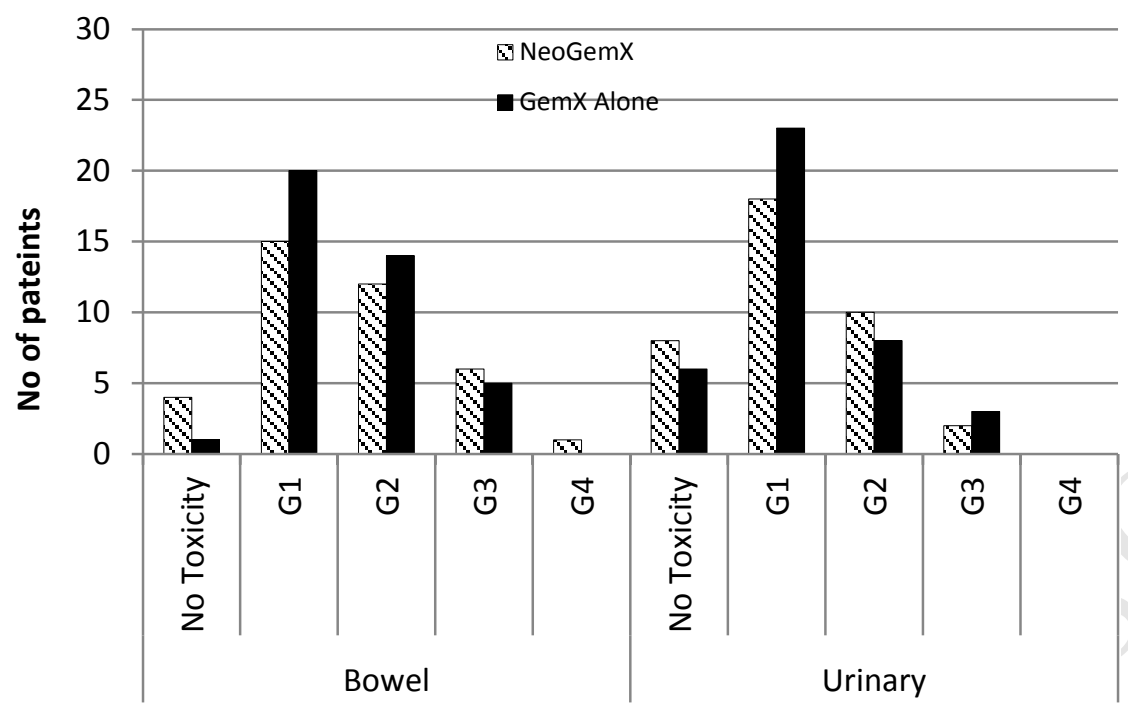

1b: Maximum late toxicity.

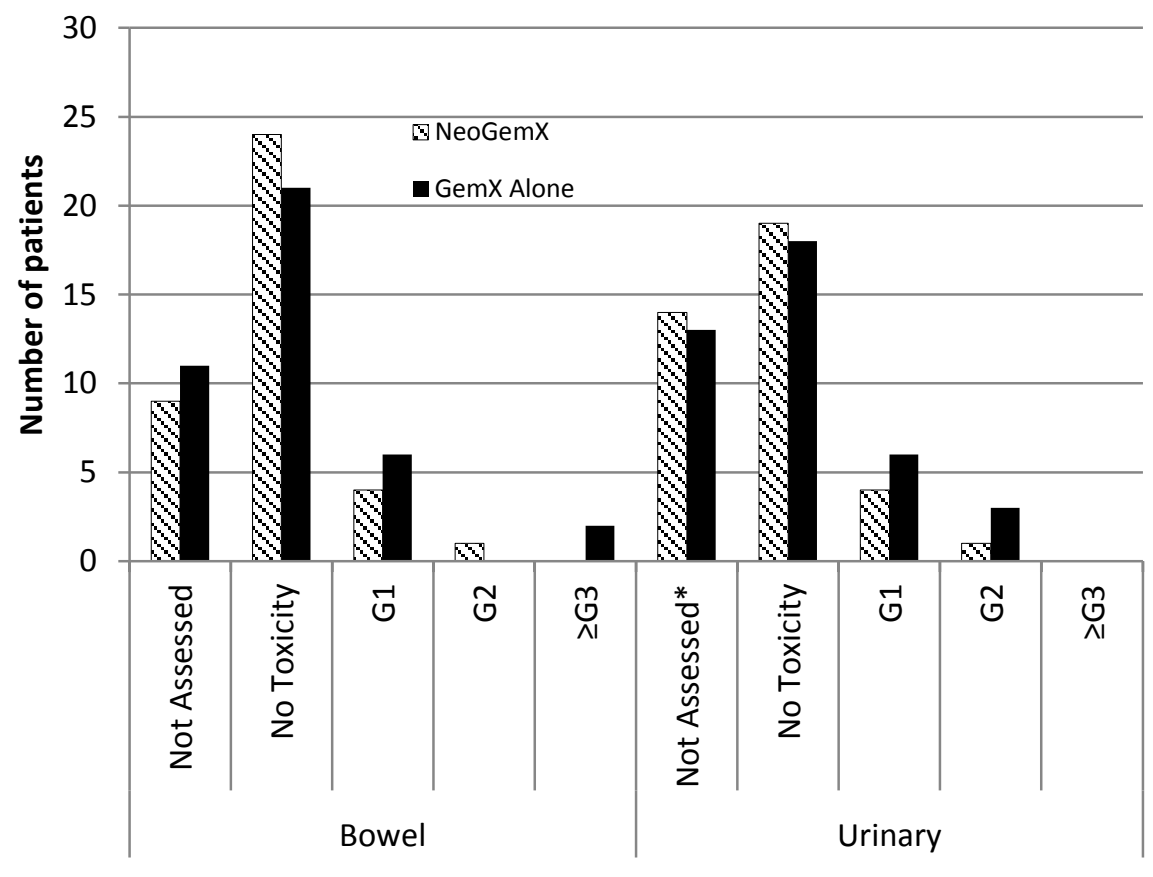

*Not assessed in 3 cases in the NeoGemX group due to cystectomy for recurrence. 


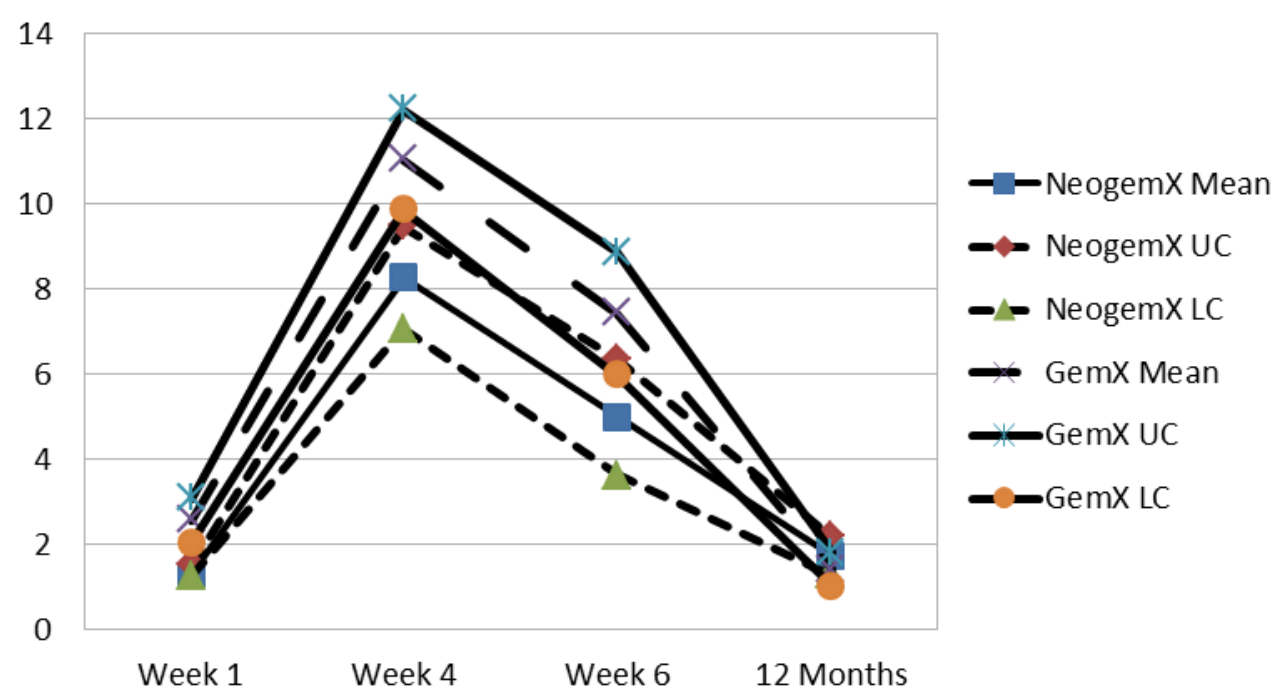

Figure 2A LENT SOMA Mean Bowel Scores for Male Patients

UC: 95\% Upper confidence limit LC: 95\% Lower Confidence limit

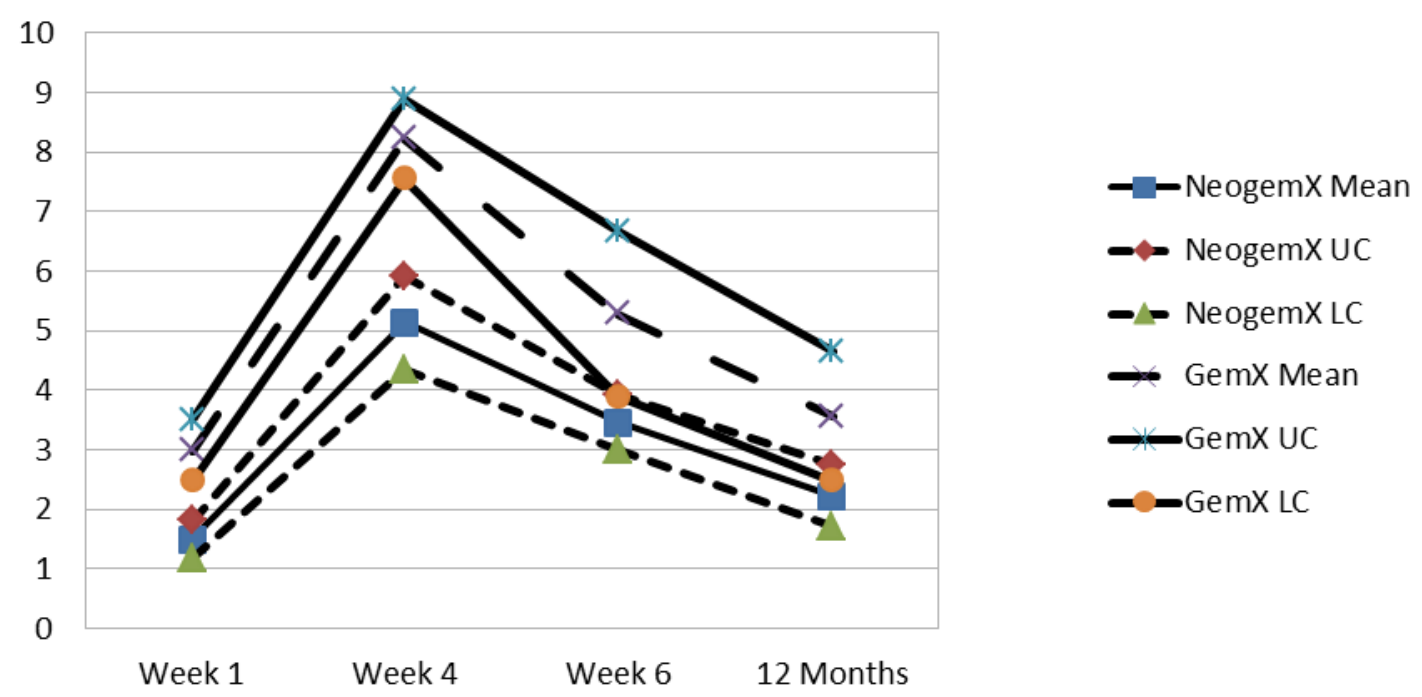

Figure 2B LENT SOMA Mean Urinary Scores for Male Patients

UC: $95 \%$ Upper confidence limit LC: $95 \%$ Lower Confidence limit 
Figure 3 A) Disease Free Survival. B) Overall Survival

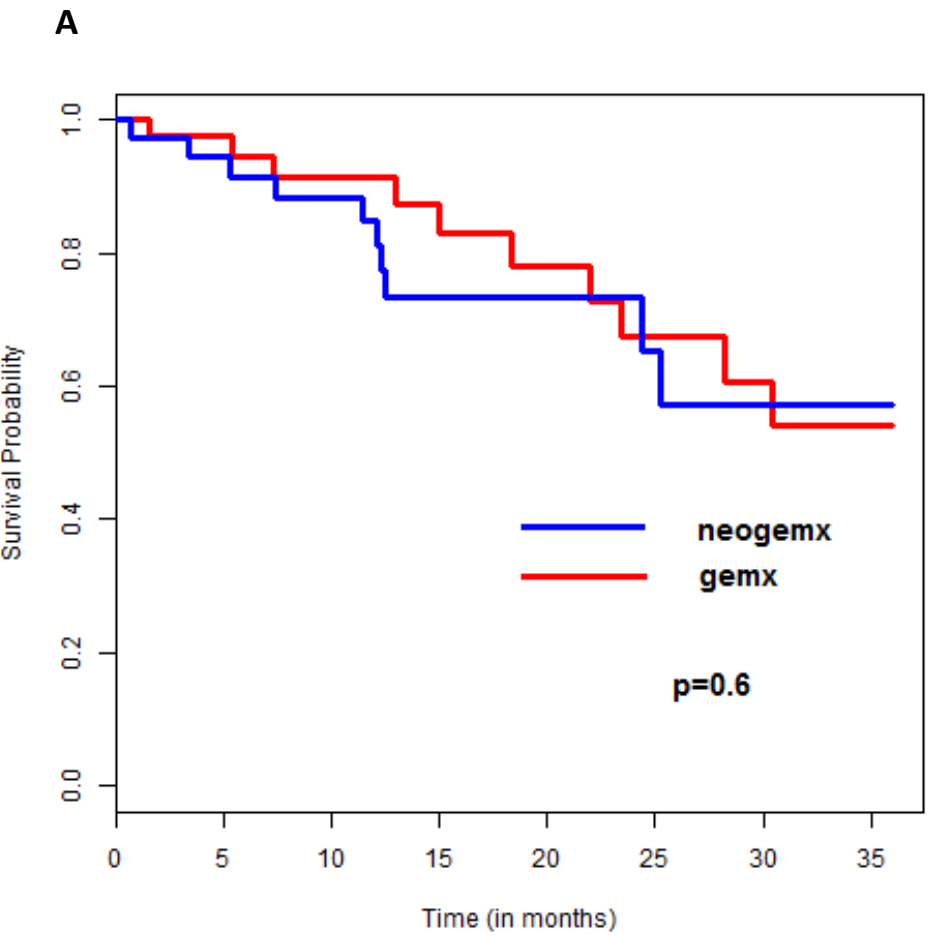

$\begin{array}{ccccccccc}\text { number at risk } & & & & & & & & \\ \text { gemx } & 40 & 33 & 27 & 20 & 16 & 14 & 9 & 7 \\ \text { neogemx } & 38 & 33 & 26 & 16 & 12 & 8 & 7 & 5\end{array}$

B

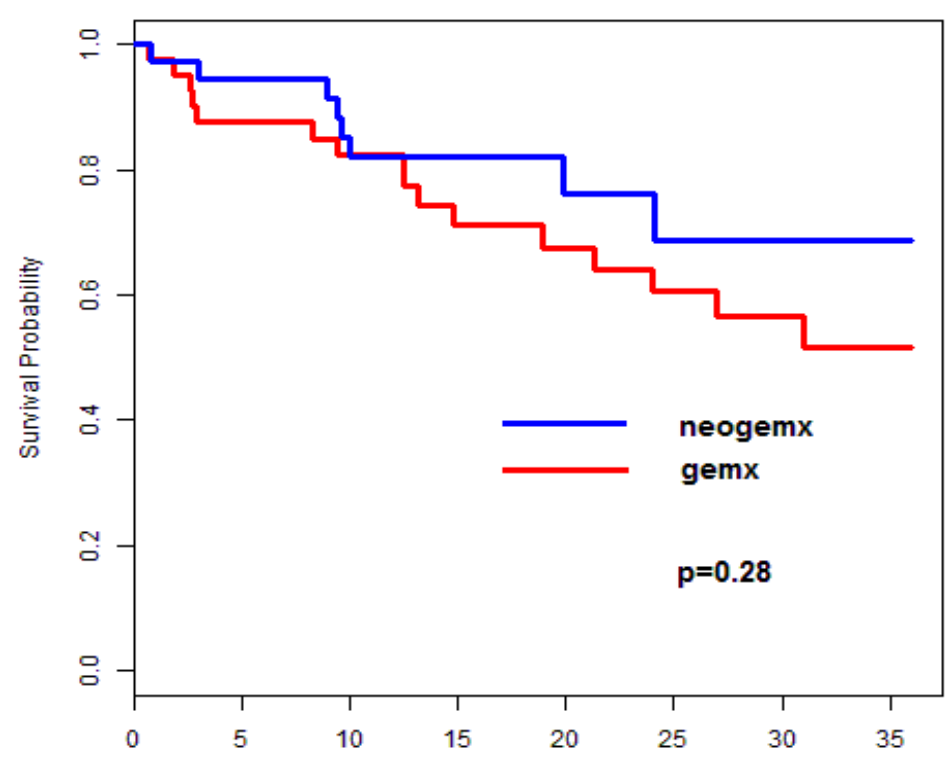

number at risk

gem $x$

neogemx

$\begin{array}{llllllll}40 & 35 & 32 & 23 & 19 & 17 & 12 & 9 \\ 38 & 34 & 27 & 21 & 14 & 10 & 9 & 7\end{array}$

